\title{
Evaluation of Corticosteroids in Treatment of Tuberculous Meningitis
}

\author{
SHANTI GHOSH, R. SESHADRI, and K. C. JAIN \\ From the Department of Paediatrics, Safdarjang Hospital, New Delhi, India
}

\begin{abstract}
Ghosh, S., Seshadri, R., and Jain, K. C. (1971). Archives of Disease in Childhood, 46, 51. Evaluation of corticosteroids in treatment of tuberculous meningitis. 98 patients with tuberculous meningitis were studied with a view to assessing the value of steroids as an adjuvant to antitubercular drugs. The patients were divided into three groups irrespective of the clinical stage of the disease. One group received antitubercular drugs alone, the second oral prednisolone, and the third intrathecal steroids, in addition to the antitubercular drugs. There was no significant difference in the mortality rate in the different groups. Oral steroid treatment lowered the CSF protein more rapidly, but did not influence the outcome nor prevent the formation of spinal block.
\end{abstract}

Steroids have been used as an adjuvant in the treatment of tuberculous meningitis since 1953. Experimentally, steroids suppress certain aspects of the inflammatory response in tuberculosis (Ebert, 1952) and have been proposed as an adjuvant in the treatment of tuberculous meningitis. Steroids have been administered either orally, parenterally, or intrathecally. Reports on the therapeutic efficacy of steroids are conflicting, with only two attempts at a controlled study (Lepper and Spies, 1963; O'Toole et al., 1969). This study was undertaken to assess the value of steroids, either oral or intrathecal, as an adjuvant in the treatment of tuberculous meningitis.

\section{Material and Methods}

This study concerns 98 patients under the age of 12 years admitted in Safdarjang Hospital, New Delhi, between 1966 and 1969. The following investigations were done to confirm the diagnosis: tuberculin test with PPD; chest and skull $x$-rays; CSF biochemistry, cellular reaction, direct smear for acid-fast bacilli (AFB) and culture using Krischner media and guinea-pig inoculation; laryngeal swab for AFB; and gastric lavage for AFB.

The CSF examination was done on admission, every fortnight till it became normal, and thereafter every month. The disease was classified into three stages according to the M.R.C. (U.K.) classification at the time of admission. Stage I: the prodromal stage of irritability (27 patients); Stage II: the transitional stage of increased intracranial pressure and meningeal symptoms

Received 20 May 1970.
(49 patients); and Stage III paralysis and coma (22 patients). The patients were divided into three groups for the purpose of treatment, irrespective of the clinical stage of the disease. Group I: (a) intramuscular streptomycin sulphate (40 mg/kg per day); (b) isonicotinic acid hydrazide ( $20 \mathrm{mg} / \mathrm{kg}$ per day orally); (c) after discontinuation of the streptomycin, thiacetazone $3.5 \mathrm{mg} / \mathrm{kg}$ per day orally.

Group II: (a) antitubercular treatment as in Group I above; (b) prednisolone ( $2 \mathrm{mg} / \mathrm{kg}$ per day orally for six weeks).

Group III: (a) antitubercular treatment as in Group I; (b) hydrocortisone intrathecally $(25 \mathrm{mg} / \mathrm{kg}$ per day for 6 days).

Table I shows the distribution of patients according to the treatment groups, with the mortality.

When first seen, of the 98 cases, 50 had convulsions, 31 generalized spasticity. Other neurological complications are detailed in Table II.

TABLE I

Treatment Group and Mortality

\begin{tabular}{l|c|c|c}
\hline \multicolumn{1}{c|}{ Groups } & No. of Patients & Died & $\%$ \\
\hline I & 36 & 14 & $38 \cdot 8$ \\
II & 42 & 12 & $28 \cdot 5$ \\
III & 20 & 11 & $55 \cdot 0$ \\
\hline Total & 98 & 37 & $37 \cdot 8$ \\
\hline
\end{tabular}

\section{Results}

Of 98 patients, 37 died (14 of Group I, 12 of Group II, and 11 of Group III). 22 patients died 
TABLE II

Neurological Complications

\begin{tabular}{l|c|c|c}
\hline \multicolumn{1}{c|}{ Complications } & Group I & Group II & Group III \\
\cline { 2 - 3 } Hydrocephalus & 2 & 1 & 0 \\
Hemiparesis & 5 & 20 & 3 \\
Optic atrophy & 0 & 7 & 4 \\
7th nerve palsy & 6 & 7 & 3 \\
6th nerve palsy & 3 & 4 & 0 \\
3rd nerve palsy & 0 & 2 & 1 \\
Multiple palsies & 0 & 2 & 0 \\
& & & \\
\hline
\end{tabular}

within one week ( 8 of them within 48 hours) and the remaining 152 to 3 weeks after the start of treatment. Of the patients who died within one week, 8 belonged to Group I, 6 to Group II, and 8 to Group III. Table III shows the mortality according to the treatment group and the clinical stage of the disease. Follow-up was possible in $\mathbf{4 2}$ cases; 16 of Group I, 21 of Group II, and 5 of Group III. The mean follow-up period was 10 months. Of the 19 patients who were lost in the follow-up, 12 had left against medical advice. 2 of these were doing well, but left for personal reasons, while in 10 the condition was deteriorating. Of the other 7 lost to follow-up, the period of follow-up ranged from 1 to 8 months (mean $3 \cdot 2$ months): 5 were normal at that time, one had cerebellar ataxia, and another 6th nerve palsy. All the 7 belonged to Group I and II.

Table IV shows the overall results of treatment in the three groups.

Group I. Two cases developed hydrocephalus, in one a shunt operation was done, and the biopsy of the arachnoid tissue showed tuberculous lesions. 3 patients discontinued the treatment after 3 months of therapy and were again admitted with fever, vomiting, convulsions, and CSF suggestive of tuberculous meningitis. All were now treated as
TABLE IV

Results of Treatment

\begin{tabular}{|c|c|c|c|}
\hline Result & Group I & Group II & Group III \\
\hline $\begin{array}{l}\text { Complete recovery } \\
\text { Recovery with some } \\
\text { residuae } \\
\text { No recovery }\end{array}$ & $\begin{array}{l}8(50 \%) \\
7(44 \%) \\
1(60 \%)\end{array}$ & $\begin{array}{l}13(61 \cdot 9 \%) \\
6(28 \cdot 6 \%) \\
2(9 \cdot 5 \%)\end{array}$ & $\begin{array}{l}0 \\
3(60 \%) \\
2(40 \%)\end{array}$ \\
\hline
\end{tabular}

for Group II. Out of 16 patients followed-up, 8 have recovered completely, 7 are left with behaviour problems, and 2 with hemiparesis.

Group II. Out of 21 patients followed-up, one had no neurological deficit, 6 patients had optic atrophy, 4 improved and regained vision. Two cases had residual hemiparesis, one patient developed a squint, 2 patients are mentally retarded and have behaviour problems. 2 patients developed symptoms of spinal block during the therapy. Intrathecal steroids were administered without striking improvement.

Group III. All 5 cases had neurological deficit. 4 developed optic atrophy, 3 improved and regained vision; 2 were left with hemiparesis and these have behaviour problems.

Response of CSF protein to treatment. The Fig. shows the CSF protein values on admission and two weeks after the treatment in the various groups. The protein levels tend to fall to normal more rapidly in the patients treated on oral steroids. In the other groups there was no change in the values.

\section{Discussion}

Kapur (1969) in a study of 103 patients (98 treated with steroids) concluded that the addition

TABLE III

Mortality According to Group and Stage of Disease

\begin{tabular}{|c|c|c|c|c|c|c|c|c|c|c|c|c|}
\hline \multirow[b]{2}{*}{ Stage } & \multicolumn{4}{|c|}{ Group I } & \multicolumn{4}{|c|}{ Group II } & \multicolumn{4}{|c|}{ Group III } \\
\hline & Total & $<1 \mathrm{w}$ & $\mathrm{d}_{1 \mathrm{wk}}$ & $\begin{array}{c}\% \text { of } \\
\text { Total }\end{array}$ & Total & $<1 \mathrm{u}$ & $\begin{array}{l}\mathrm{d} \\
1 \mathrm{wk}\end{array}$ & $\begin{array}{c}\% \text { of } \\
\text { Total }\end{array}$ & Total & $<1 \mathrm{w}$ & d $1 \mathrm{wk}$ & $\begin{array}{l}\% \text { of } \\
\text { Total }\end{array}$ \\
\hline $\begin{array}{l}\text { I } \\
\text { II } \\
\text { III }\end{array}$ & $\begin{array}{r}18 \\
17 \\
1\end{array}$ & $\begin{array}{l}3 \\
4 \\
1\end{array}$ & $\begin{array}{l}3 \\
4 \\
0\end{array}$ & $\begin{array}{r}27 \cdot 7 \\
47 \cdot 0 \\
100 \cdot 0\end{array}$ & $\begin{array}{r}9 \\
25 \\
8\end{array}$ & $\begin{array}{l}0 \\
2 \\
4\end{array}$ & $\begin{array}{l}1 \\
5 \\
0\end{array}$ & $\begin{array}{l}11 \cdot 1 \\
28 \cdot 0 \\
50 \cdot 0\end{array}$ & $\begin{array}{r}0 \\
7 \\
13\end{array}$ & $\begin{array}{l}0 \\
0 \\
8\end{array}$ & $\begin{array}{l}0 \\
3 \\
0\end{array}$ & $\begin{array}{l}0 \\
42 \cdot 0 \\
61 \cdot 5\end{array}$ \\
\hline Total & 36 & 8 & & $38 \cdot 8$ & 42 & 6 & & $28 \cdot 5$ & 20 & $\underbrace{8}$ & & $55 \cdot 0$ \\
\hline
\end{tabular}




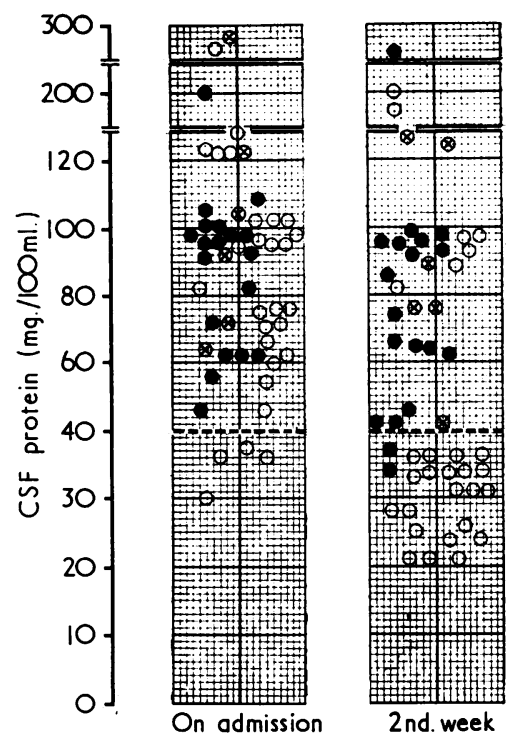

- Group I $0=$ Group II $\otimes=$ Group III

FIG.-The response of CSF protein to treatment in various groups. The protein level fell more rapidly in the patients treated with oral steroids.

of steroids to the treatment of tuberculous meningitis seemed to have significantly reduced the mortality from tuberculous meningitis. She had compared this result with that of 117 patients treated in 1962, of whom only 38 patients had received steroids. Ashby and Grant (1955), Bulkeley (1953), and Voljavec and Corpe (1960) reported similar improved survival in steroid treated patients, attributing this to the reduction in the meningeal inflammation and to a decrease in the reduction of spinal block. Lepper and Spies (1963) on the other hand were unable to detect any effect after 14 days of steroid therapy in 19 patients compared with controls. O'Toole et al. (1969), in their double-blind study of 23 patients with dexamethasone as an adjunct to the treatment in 11 patients, concluded that despite a striking influence of dexamethasone on the CSF, an improved survival was related to an amelioration of cerebral oedema. They felt that the administration of steroids in high doses was clearly indicated in the treatment of cerebral oedema associated with tuberculous meningitis. Other investigators have modified the initial enthusiasm for the routine use of the steroid therapy, reserving them for use in desperate situations (Wasz-Höckert, 1962). Toole and McCall (1969) postulated that dehydrating agents might be as use- ful as steroids in treating the secondary effects of inflammation of the meninges and the brain.

The mortality rate in the present series is $38 \%$ and there is no significant difference in Groups I and II statistically $\left(\chi^{2}=0.93\right)$ The higher mortality in Group III appears to be due to more patients in Stage III being included in this series. The mortality rates in Stage III in Group II and III are about the same. Again there is no significant difference between the deaths that occurred within one week in the various groups (8 of the 36 in Group I; 6 of the 42 in Group II; 8 of the 20 in Group III). Thus steroids failed to alter the outcome during the acute phase.

In terms of recovery, patients in Group II showed a slightly increased recovery rate compared to Group I, but this was not statistically significant $(t=0 \cdot 2309)$. As follow-up was achieved in only 5 patients of Group III, no comment can be made about the recovery rate.

That steroid treatment lowers the CSF protein level in this disorder (Chromis et al., 1957; Johnson et al., 1957; Shane and Riley, 1953) was confirmed. But whether this reduction in the protein decreases the incidence of spinal block has not been shown. In this study two patients developed spinal block during treatment with steroids (Group II) and the simultaneous administration of intrathecal steroid did not affect the course.

We are grateful to the Indian Council of Medical Research for financial assistance and to Mrs. Shantha Madhavan for statistical evaluation.

\section{REFERENCES}

Ashby, M., and Grant, H. (1955). Tuberculous meningitis treated with cortisone. Lancet, 1, 65.

Bulkeley, W. C. M. (1953). Tuberculous meningitis treated with ACTH and isoniazid. British Medical fournal, 2, 1127.

Chromis, C., Papadatos, C., Gargoulas, A., and Drosos, C. (1957). Intrathecal hydrocortisone in the treatment of tuberculous meningitis. Fournal of Pediatrics, 50, 138.

Ebert, R. H. (1952). In vivo observations on the effect of cortisone on experimental tuberculosis, using the rabbit ear chamber technique. American Review of Tuberculosis and Pulmonary Diseases, 65, 64.

Johnson, J. R., Furstenberg, N. E., Patterson, R., Schoch, H. K., and Davey, W. N. (1957). Corticotropin and adrenal steroids as adjuncts to the treatment of tuberculous meningitis. Annals of Internal Medicine, 46, 316.

Kapur, S. (1969). Evaluation of treatment of tuberculous meningitis since the use of steroids as an adjuvant. Indian Pediatrics, 6, 166.

Lepper, M. H., and Spies, H. W. (1963). The present status of the treatment of tuberculosis of the central nervous system. Annals of the New York Academy of Sciences, 106, 106. 
O'Toole, R. D., Thornton, G. F., Mukherjee, M. K., and Nath, R. L. (1969). Dexamethasone in tuberculous meningitis. Annals of Internal Medicine, 70, 39.

Shane, S. J., and Riley, C. (1953). Tuberculous meningitis. New England fournal of Medicine, 249, 829.

Toole, J. F., and McCall, C. E. (1969). Brain inflammation and steroids: two double-edged swords. (Editorial). Annals of Internal Medicine, 70, 221.
Voljavec, B. F., and Corpe, R. F. (1960). The influence of corticosteroid hormones in the treatment of tuberculous meningitis in Negroes. American Review of Respiratory Diseases, 81, 539.

Wasz-Höckert, O. (1962). Modern treatment and late prognosis of tuberculous meningitis. Acta Paediatrica, 51, Suppl. 141, 93.

Correspondence to Dr. Shanti Ghosh, 9 Shahjahan Road, New Delhi, India. 